\title{
The whole population approach to caries prevention in general dental practice
}

\author{
Martin Tickle and Keith Milsom \\ North West Strategic Health Authority \\ Martin.Tickle@northwest.nhs.uk
}

In September 2007 the Department of Health published Delivering better oral health: an evidence-based toolkit for prevention, ${ }^{1}$ which was distributed to every NHS practice in England. The toolkit provides guidance, using an evidence-based approach, to providing preventive care in general practice. For young children the toolkit advocates that all patients, including those who are caries free, should receive active preventive care; an approach dentists may intuitively find difficult to accept. Children who present caries free are perceived by many to be of low risk of developing the disease and providing prevention therapies to this group could be seen as a waste of time and resources. This perception is based on an assumption that we can accurately predict who will, and who will not, get caries. However, we have no accurate and reliable tools to identify the children who will develop caries ${ }^{2}$ and the consequences of guessing incorrectly are significant. Once a child contracts caries in the primary dentition pain and extraction are highly likely ${ }^{3}$ and once a child develops caries in their permanent teeth they are left with a lifelong legacy of maintenance of restorations.

There are other reasons why we should reject a high risk approach to caries prevention, not least because the majority of new cases of the disease arise from those children who initially present caries free. A recent study of the incidence of dental caries in young children regularly attending dental practices in the Northwest of England reported that one in four children who were caries free at their first visit went on to develop caries over a three year period and three out of four children who already had caries at their first visit went on to develop further cavities. ${ }^{4}$ As the majority of young children attending a dentist for the first time are likely to be caries free, a $25 \%$ conversion rate of children from caries free to caries active over a three year period means that the largest number of cases of caries arise from the children who initially present caries free. This work also suggests that whatever age caries starts in young children it progresses at the same rapid rate, with the same adverse consequences. So, if dentists concentrate active prevention solely on those children with caries they will be unable to prevent the majority of new cases of the disease in their practice population. This whole population approach to prevention would be questionable if the interventions were expensive or had a risk of side effects. However, the preventive therapies recommended by Delivering better oral health, fluoride varnish and fluoride toothpaste containing at least $1,000 \mathrm{ppm}$ of fluoride are cheap, safe and effective, so why not provide them to all children?

\section{DENTAL NURSES CAN NOW APPLY FLUORIDE VARNISH}

One school of thought advocates that dentists should identify early carious lesions and focus preventive resources on only those children with an early lesion, and then monitor the lesions to see if they progress. This approach overlooks the fact that the most expensive part of this process is the time of the dentist. Dental nurses can now apply fluoride varnish, so the costs of providing the preventive interventions recommended in the toolkit to all are likely to be less than paying dentists to hunt for early enamel lesions. The toolkit acknowledges that there will be some children who will have greater preventive needs, including those with special needs and those already with caries. For these children additional preventive therapies are advocated. However, the key to success in practice-based dental prevention is providing effective preventive care to the large numbers of children that are caries free and reducing the number of those children that convert to the caries active state.

There is a temptation, particularly in high need localities, for the profession to take a fatalistic view of caries, almost seeing its development as a fact of life. This cynical supposition should be challenged; life, and dental care, does not have to be this way $^{5}$. We need to take prevention seriously; it should be the thing that we do best in dentistry, not something to which we pay lip service. A first step along this path would be to set ourselves the aim that all children who present for care initially caries free should remain so.

1. Department of Health and the British Association for the Study of Community Dentistry. Delivering better oral health: an evidence-based toolkit for prevention. 2007. Gateway reference 8504. http://www.dh.gov.uk/en/Publicationsandstatistics/Publications/PublicationsPolicyAndGuidance/DH_078742

2. Harris $R$, Nicoll $A D$, Adair P M, Pine $C M$. Risk factors for dental caries in young children: a systematic review of the literature. Community Dent Health 2004; 21(1 Suppl): 71-85.

3. Tickle M, Milsom K M, Blinkhorn A S. The occurrence of dental pain and extractions over a three year period in a cohort of children aged 3-6 years. J Public Health Dent 2008; 68: 63-69.

4. Milsom K M, Blinkhorn A S, Tickle M. The incidence of dental caries in the primary molar teeth of young children receiving National Health Service funded dental care in practices in the North West of England. Br Dent J 2008; 205: E14.

5. Axelsson P. The effect of a needs-related caries preventive program in children and young adults- results after 20 years. Biomed Central Oral Health 2006; 6 (Suppl 1): S7.

DOI: 10.1038/sj.bdj.2008.985 